\title{
MUERTE Y CUERPO EN ANTÍGONA: UNA LECTURA DESDE EL PSICOANÁLISIS
}

Sebastián Patiño Villegas 


\section{DEATH AND BODY IN ANTIGONE: A READING FROM PSYCHOANALYSIS}

\section{RESUMEN}

El presente texto propone una lectura de Antígona de Sófocles a partir del análisis del discurso, orientado por los referentes epistémicos y teóricos del psicoanálisis. Lo anterior se fundamenta en que la tragedia griega, aun en el orden de lo mitológico, comporta una verdad sobre el ser humano. En ese sentido, el objetivo de este análisis es señalar la relación entre el sujeto, la muerte y el cuerpo, según la idea de "muerte simbólica" subyacente a los planteamientos de la clínica psicoanalítica, pues la marca de ser mortal implica una construcción simbólica y singular para cada persona.

Palabras clave: Antígona, sujeto, muerte, cuerpo, psicoanálisis.

\section{ABSTRACT}

This text proposes a reading of Sophocles' Antigone based on analysis of the discourse, following the epistemic and theoretical principles of psychoanalysis, given that Greek tragedy, even in its mythological sense, implies a truth about the human being. Therefore, the aim of this analysis is to point out the relationship between subject, death and body, according to the concept of "symbolic death" underlying clinical psychoanalysis, since the mark of being mortal implies a symbolic and singular construction for each person.

Keywords: Antigone, subject, death, body, psychoanalysis.

\section{AUTORES}

\section{Sebastián Patiño Villegas}

Psicólogo. 


\section{INTRODUCCIÓN}

Al escritor $y$ al texto se les atribuye un saber, y el lector en una suerte de transferencia con lo escrito, o con lo que supone de su autor, se encuentra más bien en posición de analizante que en posición de amo analista del texto. Leído en cierto modo por el texto, el lector no puede acantonarse en su interpretación; ya el escrito lo interpreta en tanto lo

hace hablar

(Ansermet, 1990, p. 80).

Si bien la práctica psicoanalítica que surge del descubrimiento freudiano se ha sostenido a partir de la implementación de un dispositivo clínico, las producciones culturales, como las obras literarias y de arte, entre otras, han servido al psicoanálisis como sostén para convocar la reflexión sobre diversas problemáticas que atañen al sujeto y que permiten la formalización de un saber (Porge, 2007). Este tipo de análisis ha tomado el nombre de "psicoanálisis aplicado", "por realizarse no con un sujeto que habla en transferencia, sino a partir de textos escritos o del material sobre el que recae la interpretación" (Díaz, 2012, p. 40).

No obstante, según Lacan (1985), lo anterior no es psicoanálisis aplicado, sino que se trata de un "método psicoanalítico; método que procede al desciframiento de los significantes sin consideraciones de una presupuesta forma de existencia del significado" (p. 727). En este trabajo, justamente, la obra Antígona se aborda a partir de lo señalado por Lacan, a fin de realizar una lectura que dé cuenta de la articulación entre el trabajo de duelo y la postura que toma la heroína en esta tragedia griega y que, de manera paralela, devele una concepción de la muerte exclusiva del orden simbólico del ser humano, por cuanto se ve atravesado por el lenguaje.

El hecho de tomar esta obra como objeto de análisis no constituye un ejercicio intelectual supeditado a intereses netamente personales y en el que se cede a excesos de interpretación. Por el contrario, hay que reconocer que, si esta obra suscita el decir del investigador, es porque en ella se halla una subjetividad implicada y son precisamente esas marcas de subjetividad las que movilizan un saber en el orden de la invención.

\section{TENER UN CUERPO: ENTRE LA VIDA Y LA MUERTE}

La instancia de la vida, la vida como transitoria, la vida del cuerpo del ser hablante, la vida del cuerpo que se consume

(Miller, 2013, p. 418).

¿Cómo es posible conocer la relación del ser hablante con la muerte? Para dar respuesta a este interrogante es necesario señalar, de antemano, que pensar la muerte solo es posible a partir de la inauguración de la vida. Así, ¿qué es entonces la vida humana? En esencia, la vida humana es un corte, una hiancia introducida en la inercia de la muerte y presentada bajo la forma del cuerpo. En otras palabras, es la nada total llamada muerte que se hace cuerpo. Esta operación obedece al choque entre la carne y la palabra. De manera que aquí, cuando se dice cuerpo, no se entiende organismo, pues no se trata del cuerpo fisiológico, el de las contracciones y pulsaciones, el que se tiende en los anfiteatros.

El cuerpo, como se postula en el psicoanálisis, es el de la desarmonía, el de la carne aguijoneada por el lenguaje, el de las pulsiones. En suma, es algo mucho más complicado que lo que consideran los anatomobiólogos (Lacan, 1973). El cuerpo, así entendido, vehiculiza los efectos del discurso, permite pensar un más allá de la necesidad biológica, es decir, permite pensar en una trascendencia en la que son ubicados los ordenamientos simbólicos que le dan existencia al cuerpo como representación imaginaria. A diferencia de la práctica médica, encargada de observar, des- 
cribir y clasificar la enfermedad como manifestación del organismo, el psicoanálisis se ocupa de cómo el organismo deviene cuerpo, una vez que este aparece se constituye en eslabón de una cadena significante, y de cómo el "viviente" deviene "sujeto".

Desde esta perspectiva, se advierte que el ser hablante surge, no por un desarrollo natural pautado y preordenado, sino por ocupar ya y siempre un lugar en el espacio simbólico. Dice Miller (2002): "si bien es lícito, para el animal, identificar el ser y el cuerpo, no lo es para la especie humana. Ello concierne al estatuto del cuerpo hablante: el cuerpo no compete al ser, sino al tener" (p. 17). Por ende, decir "tengo un cuerpo", tomarlo como atributo y no como "ser" solo es posible en la medida en que, como seres atravesados por el lenguaje, podemos prescindir de él.

El sujeto es alguien nombrado, insertado en el universo del discurso antes de poder hablar, antes de tener un cuerpo, y permanece ahí aun después de no tenerlo, es decir, después de la muerte. Una vez ubicado en el discurso, el sujeto empieza a tener un cuerpo animado por el deseo del "otro". Esto se puede ilustrar a partir de la figura del recién nacido, el cachorro humano ${ }^{1}$. Este sobrevive, fundamentalmente, por la mediación del deseo del otro, quien llega a él bajo la forma de un ofrecimiento, de un don de lo que puede satisfacer sus necesidades. El todavía-no-sujeto es, pues, indiferente ante la posibilidad de vivir o morir. Pero alguien, otro, su madre, quiere que él viva. De esta manera, al aceptar el don se pone en el lugar

\footnotetext{
$1 \quad$ Aunque es Lacan (1949/2013) quien, en El estadio del espejo como formador del yo (je) tal como se nos revela en la experiencia psicoanalítica, se refiere a la prematuración específica del hombre, ya Freud, en su texto Proyecto de psicología para neurólogos (1885/1950), había hablado de la indefensión del cachorro humano en sus primeros tiempos, refiriéndose al embarazo demasiado corto de la madre en comparación con el de otros mamíferos.
}

del deseo del otro, lo que le implica, a su vez, aceptar sobrevivir, iniciar el trabajo para encontrar el propio camino hacia la muerte.

\section{MUERTE Y CUERPO: EL MÁS ALLÁ DE LA VIDA ABIERTO AL SER HABLANTE}

Cuando Freud se pregunta por la muerte en el hombre lo hace a partir del concepto de pulsión. Ya en Más allá del principio del placer (1979) establece el binomio pulsión de vida -pulsión de muerte, afirmando que durante la animación de lo inorgánico se separan las pulsiones de vida y de muerte y que el misterio de la vida reside en la lucha antagónica de ambas. Sin embargo, en el segundo capítulo de su texto De guerra y muerte. Temas de actualidad (1915), dice que la propia muerte no es representable más sí anticipable: "es la muerte ejerciendo una fuerte influencia sobre la vida, según si se acepte correr el riesgo de la muerte o que se excluya el riesgo en una postura nada heroica" p. 298): esto plantea la idea de un más allá de la vida.

Este más allá de la vida no es metafísico, sino que está abierto al ser hablante por el lenguaje. Es un más allá que se materializa gracias a la sepultura, puesto que solamente para la especie humana el cuerpo muerto conserva su valor (Miller, 2002). De esta manera, la duración del sujeto, al estar sostenida por el significante, excede a la temporalidad del organismo, ya que el lenguaje otorga un margen temporal que Lacan llama "el margen más allá de la vida", un margen que hace referencia al cuerpo viviente, tanto en la anticipación del sujeto antes de nacer como en la memoria que de él se guarda a partir de la sepultura.

De este más allá de la vida que está abierto al cuerpo hablante, el personaje de Antígona es en sí mismo el ejemplo. Lacan, en La ética del psicoanálisis, ahondó en la raíz trágica de la experiencia analítica a través de la Antígona de Sófocles, ya que, como Freud supo enseñar, la tragedia nos concierne a todos y a cada 
uno. Antígona, dice Lacan (1959-60/1990), "permite ver el punto de mira que define el deseo [...] una imagen que hacía cerrar los ojos en el momento en que se la miraba" (p. 208).

Así, el verdadero alcance de la tragedia resulta no ser otro que el 'brillo', la bella imagen que corresponde con lo real del objeto de la heroína trágica; bella por cuanto llega a encarnar el deseo, la pulsión de muerte en estado puro. Su brillo, entonces, obnubila y, en consecuencia, vela el horror frente a la muerte. Es, dice Lacan (1959$60 / 1990$ ) "evidentemente, porque lo verdadero no es demasiado bonito de ver que lo bello es, si no su esplendor, al menos su cobertura" (p. 288). Al pensar así la imagen como función estética, se concibe la existencia de un límite, sobre todo, en términos de negación y ausencia, como una línea que separa lo visible de lo no visible. El límite se describe entonces como "una frontera que separa dos campos diferenciados y que parecen excluirse mutuamente: lo visible y lo invisible, lo imaginario y lo simbólico, la vida y la muerte" (Weber, 1997, p. 55).

Antígona es una tragedia que permite dar cuenta de cómo las inscripciones sobre el cuerpo, alzadas sobre el fondo común de la palabra y de la muerte, inauguran caminos distintos en la lógica del viviente, pues la vida, el cuerpo, el otro, la ley y sus marcas no existen fuera del lenguaje, como tampoco existe la muerte misma ni el saber construido sobre ella. Por su parte, el significante no es posible sin la muerte, ya que se hace necesario matar el vacío de la nada, para que surja la representación y, como tal, la vida. En este sentido, Lacan (1953/2009) reivindica que "el símbolo se manifiesta, en primer lugar, como asesinato de la cosa, y esta muerte constituye en el sujeto la eternización de su deseo" (p. 306). Es, justamente, en aquella relación entre la vida, la muerte y el significante que se abre para Antígona la posibilidad de construir un cuerpo signado por el goce y el deseo y, asimismo, el hecho de ser representada por un síntoma o, más aún, de ser un síntoma.

\section{ANTÍGONA Y LA SEGUNDA MUERTE}

Habrá que preguntarse en principio por el personaje de Antígona, ¿quién es ella?, ¿a qué apunta su esencia? Es la heroína trágica (y aquí la connotación de lo trágico no se deriva de su lamento). Tal concepción se funda, más bien, en la relación agonística entre ella y la ley, en la dialéctica de la colisión entre la ley familiar, su ley particular, y la ley del otro, la del Estado. Antígona es pues un sujeto dividido, un sujeto atravesado por un "no-saber" y que solo puede desear de acuerdo con las leyes del lenguaje. Por ende, el deseo de Antígona es deseo del otro, por cuanto se encuentra en el campo del lenguaje; es deseo que está basado por un significante que le viene del otro, en este caso, representado por Creonte, tío de Antígona y rey de Tebas.

Es Creonte el que decreta no enterrar a Polinices, quien, en pro de arrasar la tierra patria en la guerra de los Siete Jefes, lucha con su hermano Eteocles; finalmente, los dos encuentran la muerte. Antígona, hermana de ambas víctimas, se introduce así en lo que Lacan denomina entre dos. Por un lado, debe elegir entre la norma impuesta, la ley de la ciudad, que exige la no sepultura de su hermano y la ley divina, que le indica hacer honor a su linaje y evitar la deshonra de dejarlo insepulto, a merced de las aves. Por otro lado, se debate entre dos muertes: la muerte orgánica de Polinices y su muerte simbólica, esta última posible en la medida en que Polinices sigue existiendo en el orden del lenguaje, como significante que aún representa algo para otros significantes.

Es entonces cuando resulta posible entrever otra manera de pensar el límite, es decir, la muerte. Cuando se inicia la tragedia, Antígona no se pregunta nada. Esto se evidencia cuando ella dice: "yo voy a enterrarle, y, habiendo yo así obrado bien, que venga la muerte". ¿Qué es esta muerte simbólica que, en el fondo, es la segunda muerte? Es una muerte que está presente en la vida y que individualiza a la muerte natural, 
pues no ha de morir un organismo, sino ese que fue significante. Es una muerte que eterniza con el mismo movimiento con el que paraliza al cuerpo viviente, que trasciende el retorno a lo inanimado y que asegura una sobrevida en el orden del lenguaje. En palabras de Lacan (1953/2009), es la "única vida que perdura y que es verdadera, puesto que se transmite sin perderse en la tradición perpetuada de sujeto a sujeto" (p. 306).

Por otro lado, Antígona reconoce el derecho a la sepultura que ha de tener el viviente humano, es decir, apunta a la persistencia del significante más allá de la muerte biológica. Mantiene el derecho de la existencia del significante del uno más allá de los atributos que pudieron serle otorgados. La cuestión no es tanto si Polinices ha sido bueno o malo o si es culpable o no, sino que ha sido sujeto del significante, lo cual es acentuado por Antígona cuando se dirige a Creonte y le dice:

Polinices, él es todo lo que usted quiera, sin duda, no tiene el mismo derecho que el otro, ya puede usted contarme lo que quiera, que uno es el héroe y el amigo, que el otro es el enemigo, pero yo le contesto que este orden que usted se atreve a intimarme no cuenta para nada, pues en todo caso, para mí, mi hermano es mi hermano (Sófocles, 2004, p. 55).

Con esto Antígona se refiere a la irreductible singularidad, a lo absoluto del sí mismo de un hermano muerto que se revela irremplazable, no como individuo biológico, sino como hermano. En este punto, se debe señalar que la diferencia entre el sujeto en cuestión y el individuo es que el último cree ser poseedor del lenguaje, aquel que mantiene el espejismo de que el discurso es una herramienta para su hacer, mientras que el sujeto que nos muestra el psicoanálisis es un sujeto llevado por la cadena significante sin que él mismo lo aprecie. Antígona es llevada a su acción comandada por algo que la precede. Si bien hay una elección, esta se orienta por el discurso que está ahí desde siempre, incluso antes de que ella aparezca. Por tal razón, Lacan afirma que Antígona es la perpetuadora de la Até ${ }^{2}$ familiar, es decir, de la fatalidad familiar que la precede y a la cual tiene acceso a través de lo real del síntoma. Este síntoma se entiende en la medida en que es presencia, marca, corte del significante del otro en su cuerpo. No en vano el corifeo le dice: "superando a todos en valor, te acercaste sonriente hasta rozar el elevado asiento de Dike. Tú cargas con la culpa de algún crimen paterno" (Sófocles, 2004, p. 75).

He aquí el sentido de lo sintomático en Antígona, el cual no se alcanza totalmente ni con el significante ni con la verdad reprimida. Es algo dado en el orden de lo real por cuanto impide que las cosas anden (que anden en el sentido de que Antígona dé cuenta de sí misma de manera satisfactoria, al menos, para la ley). Es decir, lo sintomático es lo real en la medida en que le impide transitar al paso que le exige la ley decretada por Creonte. Esta es su invención sintomática, un síntoma ${ }^{3}$ que no está dirigido al otro de la ley, pues no es un mensaje, sino una forma de hacer algo con el imposible del duelo por la pérdida del objeto amado.

2 En la tragedia, la Áte familiar evoca el extravío, la calamidad y la fatalidad. Lacan insiste en que la Áte que depende del otro es el lugar donde se sitúa Antígona, es decir, que ella parece estar poseída por el otro, la maldición familiar, los dioses, el destino, sin mediaciones. La Áte se muestra como lo que fija el límite que no debe ser transgredido, lugar que, no obstante, la propia Antígona transgrede.

3 El síntoma constituye aquello que padece el ser y, al mismo tiempo, es el intento de curación que el propio sujeto del inconsciente encuentra. En este sentido, el síntoma es portador de un saber no sabido por el sujeto y que es posible descifrar. Entonces, si se tiene en cuenta que es la "solución problemática", se reconoce, a su vez, la importancia de no acallarlo, de no eliminarlo, pues este funciona como una metáfora, como una forma de anudamiento, para no caer en la angustia de lo real y, en efecto, señala la posición del sujeto ante su malestar. 
Ahora bien, se debe destacar que el deseo de Antígona por hacer cumplir la ley no escrita, su ley, esa que la llevó a la sepultura de su hermano y posteriormente a su propia muerte, solo empezó a adquirir un sentido una vez que la comunidad comenzó a atribuirle una función en esencia sintomática: la de señalar el límite de lo bello y los efectos de la transgresión, la de develar el horror de la muerte. Antígona, entonces, no solo se hace representar por un síntoma, sino que es síntoma en la medida en que inaugura o, mejor, en la medida en que actualiza un malestar en la cultura, el malestar de la incidencia de lo ominoso, de lo horroroso que nace del encuentro con lo real de la muerte.

De manera que, tanto para Creonte como para el pueblo, Antígona encarna un síntoma en la medida en que les implica un encuentro con lo real, eso ante lo cual solo pueden responder sintomatizándolo. Por tal razón, la tarea de los mensajeros trágicos ha de ser nombrar eso intolerable que sucede fuera de escena, eso que hace síntoma en el ámbito social, al señalar la pobre criatura que es el hombre y que, en su conjunto, quiere ser velado, persistir en su carácter de no-sabido. ¿Qué es eso que en Antígona está fuera de escena? En principio, es el cadáver de Polinices en su inhumana condición de insepulto y, después, es la propia Antígona, muerta entre los vivos y viva entre los muertos.

La actitud de Antígona en esta tragedia tiene, como ya se ha señalado, un lugar, precisamente, el hecho de estar entre estas dos muertes: la real, y la simbólica. Ese lugar es el que resalta Lacan como fuente de su brillo, el brillo de una mujer joven cuyo resplandor hace que el público se obnubile, que no pueda ver. $Y$ es precisamente en este sitio en el que puede señalarse que tal brillo vela un más allá, un vacío que atenúa la desesperación de lo que hace estragos por incomprensible, esto es, el horror a la nada, a la muerte que se nos abre en cuanto el significante choca con la carne, acontecimiento traumático original, momento en el que el goce marca el cuerpo inscribiendo el goce de la vida.

Ahora bien, es menester reconocer que solamente en aquel momento en que lo pulsional pasa por el otro, Antígona puede encontrar un modo de satisfacción que limita el sufrimiento que le supone la elaboración de la pérdida de su hermano Polinices y que le permite, a su vez, encontrar una utilidad, bajo el modo de una invención, como solución creada: la de su ética, la de actuar conforme al deseo que la habita, la de saber hacer algo con eso, con la tragedia familiar que cargó $y$ con las marcas que hizo el otro en su cuerpo.

Es así que desde Antígona ha de leerse el síntoma como verdad cifrada que comporta un sentido que se ofrece para su interpretación. El síntoma es Antígona cuando dice: "¿Quién es el que, teniendo que vivir como yo en medio de innumerables angustias, no considera más ventajoso morir?" y es el corifeo cuando expresa: "Y yo también ahora, al ver lo que estoy viendo, me siento inclinado a desobedecer las leyes, y no puedo retener el raudal de mis lágrimas contemplando cómo Antígona avanza hacia el lecho, el lecho nupcial en que duerme la vida de todos los humanos".

\section{REFLEXIONES FINALES}

La elección de Antígona da cuenta de una historia anudada sobre algo que hace cuerpo, que hace marca y que, en esencia, es necesario situar en el orden del decir. En otras palabras, se trata de un acontecimiento del cuerpo que hace síntoma por cuanto aparece como una solución problemática de Antígona: la de saber hacer frente a lo real que irrumpe a partir de la pérdida de sus hermanos; la falta que indica lo insoportable, lo imprevisible, lo que vuelve al mismo lugar. Esta operación ha de tener lugar solo a partir de la intervención del otro como mediador de la relación propia con ese cuerpo 
implicado ya para siempre en la muerte, así como a partir de la puesta en escena de un juego simbólico en donde el rito permite movilizar los significantes que hacen parte de la historia del sujeto. Solo de esa manera le fue posible a Antígona establecer una relación singular con la memoria de los muertos, así como una reedición, un reordenamiento de los vínculos libidinales que la entrelazaban con lo que para ella había significado cada hermano.

En este sentido, en cuanto al plano de la relación del sujeto con la muerte, se debe reconocer como transgresión epistémica el hecho de despojar a la muerte del campo del lenguaje para llevarla a terrenos ajenos, allí donde se entremezcla con los procesos desarrollados en la materia inanimada. Es en el significante y a causa de la articulación del sujeto a una cadena significante que le será posible a este último consentir el hecho de poder faltar en la cadena de lo que él es. Por tanto, la muerte y el duelo, como elaboraciones simbólicas, ordenadoras de lo real, han de tratarse de una ficción indispensable para organizar teóricamente la realidad de un destino: el del ser hablante. Para ello, es menester advertir el peligro de obturarlas, de cerrarlas con el candado de la verdad, pues algo, tanto de la muerte como del duelo, deberá permanecer siempre como lo imposible, como lo que solo existe "no siendo".

Es así que emerge la posibilidad de un sujeto de deseo, uno que se mueve entre la demanda que lo constituye y aquella que él articula, capaz de vehiculizar la palabra para hacer algo con eso que se siente como insoportable. Es un movimiento que inaugura la insatisfacción y que subraya, una y otra vez, la falta-en-ser, el vacío estructural, pero que, paralelamente, introduce las posibilidades de construir un cuerpo que goza siguiendo las coordenadas del deseo y de existir cada día dejando marcas en otros cuerpos y de matar la muerte a partir de la palabra.

\section{REFERENCIAS}

Ansermet, F. (1990). La psicosis en el texto. Buenos Aires: Manantial.

Díaz, C. (2012). Sobre el sujeto de la investigación en psicoanálisis. En D. Carmona, Sujeto y objeto en la investigación psicoanalítica (pp. 30-45). Universidad de Antioquia: Departamento de Psicoanálisis de la Facultad de Ciencias Sociales y Humanas.

Freud, S. (1979). Más allá del principio del placer. Psicología de las masas y análisis del yo y otras obras (J. L. Etcheverry, trad.). Buenos Aires: Amorrortu (Obra original publicada en 1920).

Freud, S. (1978). Publicaciones prepsicoanalíticas y manuscritos inéditos en la vida de Freud (J. L. Etcheverry, trad.). Argentina: Amorrortu Editores (Obra original publicada en 1885).

Lacan, J. (1990). El Seminario. Libro 7. La ética del psicoanálisis. Buenos Aires: Paidós. (Obra original publicada en 1959-1960).

Lacan, J. (1973). Seminario XXI. Los no incautos yerran (lección del 20 de noviembre 1973). Recuperado de: http://www.bibliopsi.org/docs/lacan/26\%20 Seminario\%2021.pdf

Lacan, J. (1985). Juventud de Guide o la letra y el deseo. En: Escritos 2, 10. ${ }^{\text {a }}$ ed. México: Siglo XXI.

Lacan, J. (2009). Función y campo de la palabra y del lenguaje en psicoanálisis. En: J. Lacan. Escritos 1 (pp. 227-310). Argentina: Siglo XXI. (Obra original publicada en 1953).

Lacan, J. (2013). El estadio del espejo como formador de la función del yo (je) tal como se nos revela en la experiencia psicoanalítica. En: Escritos 1. Buenos Aires: Siglo XXI. (Obra original publicada en 1949) 
Miller, J. A. (2002). Biología lacaniana y acontecimiento del cuerpo. Buenos Aires: Colección Diva.

Miller, J. A. (2013). Los cursos psicoanalíticos: Piezas sueltas (G. Arenas, trad.). Buenos Aires: Paidós.

Porge, E. (2007). Transmitir la clínica psicoanalítica. Freud, Lacan, hoy. Buenos Aires: Nueva visión.

Sófocles. (2004). Antígona (S. Albano, trad.). Buenos Aires: Quadrata.

Weber, S. (1997). Lacan con los filósofos. México: Siglo XXI Editores. 